\title{
A RUA: UM LUGAR DE FORMAÇÃO
}

Dionizia Portella Ghiggi

SINTESE - Um número significativo de crianças e adolescentes vive hoje nas ruas das cidades. Para esses sujeitos, as instâncias primordiais de formação como a familia e a escola, foram substituídos por outras que se situam no âmbito da rua. Demonstrar como ocorre essa formação a partir do referencial foucaultiano constitui-se no principal propósito deste texto.
ABSTRACT - Nowadays, a significant number of children and adolescents hang out on the streets of cities. For these subjects, the primary instances of education such as family and school have been replaced by others situated in the ambit of streets. Demonstrating how this education takes place under the Foucaultian referential is the aim of this paper.

\section{1 - Introdução}

O presente trabalho refere-se à dissertação de mestrado desta autora, "A rua: um lugar de formação",' que procurou centrar-se no seguinte problema: Como se vem efetivando o processo de formação das crianças e dos adolescentes que vivem nas ruas de Pelotas, de 1983 a $1994 ?^{2}$

A hipótese central desta pesquisa é que o processo de formação das crianças e dos adolescentes de rua de Pelotas efetiva-se através de relações de poder-saber, estabelecidas entre eles mesmos e outras instâncias.

O objetivo é reconstituir, a partir dos discursos das crianças e adolescentes de rua e da teoria foucaultiana, as condições e os efeitos do processo de formação instituídos pela rua, bem como identificar os principais agentes formadores nesse espaço, apontando as estratégias e os instrumentos utilizados.

Busca-se também auxiliar pessoas e instituições que se dedicam à problemática em questão, no sentido de, partindo da análise realizada, poderem obter subsídios que lhes permitam melhor qualificar suas atuações e/ou construir novas alternativas de atendimento a essas crianças.

Querer captar o processo de formação desses sujeitos justifica-se essencialmente pelos índices alarmantes de crianças e de adolescentes que vivem, hoje,

Mestre em Serviço Social pela PUCRS. Assistente social da 5a Delegacia Regional Penitenciária.

- Trabalho articulado à linha de pesquisa Formação, Trabalho e Cidadania ligada ao Mestrado de Serviço Social da PUCRS sob a coordenação da prof ${ }^{4}{ }^{\mathbf{a}}$ Julieta Beatriz Ramos Desaulniers.

2 Foi estabelecido o ano limite de 1983 porque, neste periodo, os entrevistados estavam com 7 anos, época em que saíram de casa para as ruas. E o ano de 1994 por ser o ano de realização da pesquisa de campo.

\begin{tabular}{|l|l|l|l|l|l|}
\hline VERITAS & Porto Alegre & v. 42 & $\mathrm{n}^{2} 2$ & Junho 1997 & p. 223-234 \\
\hline
\end{tabular}


nas ruas das cidades brasileiras, inclusive em Pelotas, que não foge à regra. E, ainda, por acreditar-se que esse problema não requer intervenções repressivas, mas sim educativas, intervenções capazes de restituir, em alguma medida, os direitos que essa parcela da população brasileira, dentre outras, nunca teve respeitados.

A pesquisa de campo foi realizada junto a trinta crianças e adolescentes (15 meninos e 15 meninas), entre 10 e 18 anos, que participaram dos Projetos: Atendimento ao Menor Abandonado de Rua - AMAR, e Beija-Flor; e Casa Madre Madalena. A entrevista semi-estruturada foi o principal instrumento de pesquisa.

Para captar a dinâmica das relações de poder-saber estabelecidas entre as crianças e os adolescentes de rua e os vários agentes envolvidos em tal processo, foram utilizados cinco parâmetros indicados por Michel Foucault em seu artigo intitulado El sujeto y el Poder e exibidos no item procedimentos metodológicos.

No sentido de compreender a produção dos saberes advindos das relações de poder-saber, lança-se mão das interpretações que Gilles Deleuze elabora a respeito do saber, de acordo com a concepção foucaultiana.

\section{2 - Pressupostos teóricos}

\section{1 - Formação e formado}

O termo formação, do latim formatione, é composto pelo radical verbal forma mais sufixo nominal latino tione. ${ }^{4}$ Pode-se inferir, portanto, que formação é a ação pela qual algo se forma, é produzido. Esse algo, pode ser um animal, um vegetal ou um mineral. Quando se refere ao ser humano, diz respeito à maneira como o mesmo foi moldado para viver em sociedade. Portanto, formado (a) é aquele(a) que recebeu uma certa forma, que foi habituado a ser conforme tal forma ou tal feitio.

Aqui, entende-se formação como o processo de sujeição do ser humano a uma cultura, em especial, aquele que diz respeito às "práticas divisórias". ${ }^{6}$ Segundo Foucault, essas práticas nada mais são do que uma técnica, uma forma de poder que se exerce sobre o cotidiano das pessoas, classificando-as em categorias, designando-as por sua própria individualidade, atando-as a sua própria identidade e impondo-lhes uma lei de verdade que devem reconhecer e que os outros devem reconhecer nelas. É uma forma de poder que transforma os individuos em sujeitos. ${ }^{6}$

Na rua, nas calçadas, não existem o pai, a mãe ou a professora, considerados como os primeiros e principais responsáveis pela formação das crianças. No en-

3 Sobre a temática da formação ler DESAULNIERS, Julieta Beatriz Ramos. Trabalho: a escola do trabalhador? Tese de Doutorado, defendida em 1993, junto ao PPGEd/UFRGS.

1 De acordo com Coutinho (1976:170) o sufixo tione denota ação ou resultado dela.

6 Foucault (1988:3) ocupou-se em seus estudos de três modos de objetivação que transformam os seres humanos em sujeitos, quais sejam:

- os modos de investigação que tratam de outorgar-se a si mesmos o status de ciência;

- modo como o ser humano se converte a si mesmo em sujeito;

- as práticas divisónias - o sujeito encontra-se dividido no seu interior e dividido dos outros. Ex.: 0 louco e o prudente, o enfermo e o são.

6 Para Foucault (1988:7) há dois significados para a palavra sujeito: submetido a outro através do controle e da dependência; e sujeito atado a sua própria identidade pela consciência ou conhecimento de si mesmo. 
tanto, existem o colega da turma, o policial, o brigadiano, o curador de menores, dentre outros, que, sem perceberem e serem percebidos, assumem a função de formadores.

As obras assistenciais destinadas ao atendimento das crianças e jovens de rua também fazem parte desse processo, visto que estes passam a maior parte do tempo circulando entre os mocós' e as instituições.

Em sintese, a concepção de formação utilizada no presente estudo parte do pressuposto de que as pessoas tornam-se sujeitos a partir de relações de podersaber que se estabelecem entre elas, no caso, um processo que não está baseado em um determinado sistema de valores, mas em vários. Onde os princípios éticos e morais também são os mais diversos, mas que, de uma forma ou de outra, acabam sendo colocados em ação de maneira prática e teórica, e cujo resultados, ainda que possam ser os mais diversos, parecem tender a uma homogeneidade."

\section{2 - A formação como resultado das relações de poder-saber}

Por mais democrático que se tente ser em qualquer relação que se estabeleça com uma pessoa, seja em nível formal ou informal, haverá sempre uma relação de poder-saber. É importante ressaltar que não se faz referência aqui, ao poder enquanto relação de violência, mas enquanto relação de forças, que é a maneira como Foucault o entende. A violência destrói ou altera a forma de corpos, objetos ou seres determinados, enquanto a força não tem outro objeto além de outras forças, não tem outro ser além da relação: "é uma ação sobre a ação, sobre as ações eventuais, ou atuais, futuras ou presentes" (Deleuze, 1991:78).

Portanto, para Foucault, induzir, desviar, tornar fácil ou difícil, ampliar ou limitar, tornar mais ou menos provável, etc. são as categorias do poder. $\mathrm{O}$ poder não é algo que se possa ter, porque não existe. $\mathrm{O}$ que existe são práticas ou relações de poder. O poder é uma prática social e, como tal, só pode ser exercido. É nas relações mais elementares vividas no cotidiano que o poder se exerce e deixa a sua marca mais profunda na vida dos seres humanos e da sociedade. Esse tipo de poder, quase imperceptivel, denominou Foucault de micropoder ou subpoder.

O poder é produtivo e transformador, pois ao mesmo tempo em que induz os homens a agirem de determinada maneira, conforme as regras do seu convivio social, é capaz de converter esse controle em desafio, em resistência, produzindo mudanças. Isso só é possivel porque o poder não se encontra em um ou outro indivíduo, mas está presente nas relações que eles mantêm entre si. Além disso, o fundamental na tese de Foucault (1993 b: X), é que o poder produz saber e, mais do que isso, "é um instrumento de análise capaz de explicar a produção dos saberes".

Termo utilizado pelas crianças e adolescentes de rua para se referirem aos locais que eles transformam em suas moradias (geralmente casas abandonadas).

Mocó [Do tupi mó kó], entre outros significados, quer dizer mamifero roedor da familia dos cávidas, semelhante a cobaia (Ferreira, 1975:933).

8 Existem desde marginais até cidadãos (ãs) honestos (as) que um dia foram meninos (as) de rua. A tendência, entretanto, é tornarem-se adultos marginalizados reproduzindo a situação que os originou (Sudbrack, 1982:18). 


\section{Conforme a teoria foucaultiana,}

"Não há relação de poder sem a constituição de um campo de saber, como, também, reciprocamente, todo saber constitui novas relaçōes de poder. Todo ponto de exercício do poder é, ao mesmo tempo, um lugar de formação do saber. E, em contrapartida, todo saber assegura o exercicio de um poder" (Machado, 1981:199).

Ao tornar-se alvo do poder, o indivíduo torna-se objeto do saber e, por sua vez, esse saber constituirá novas relações de poder.

Cabe ressaltar que Foucault se deteve em seus estudos apenas à região dos discursos científicos. Ele se ocupou do saber em sua relação com as figuras epistemológicas e as ciências, entretanto, admite que se pode, "do mesmo modo, interrogar o saber em direção diferente e descrevê-lo em outros feixes de relações. A região da episteme foi a única explorada" (Foucault, 1987:222), o que vem dificultar e restringir este trabalho, que trata de um tipo de saber, denominado por muitos de saber popular.

Entenda-se por saber popular aquele saber que não está sistematizado de acordo com os modelos cartesianos da ciência oficial e que se faz presente no cotidiano do camponês, do pescador, do artesão, enfim, das pessoas simples que não passaram pelo sistema oficial de ensino.

As crianças e os adolescentes de rua também fazem parte desse grupo. Mesmo expropriados culturalmente e submetidos a relações de poder-saber com diferentes instâncias e pessoas de distintos niveis de conhecimento, esse mundo infanto-juvenil cria e recria estilos, formas e sistemas próprios de saber: saber-ser, saber-fazer.

Se por muito tempo o saber dos homens e das mulheres, trabalhadores do povo, foi considerado vazio de lógica, o que pensar do saber dos marginais e criminosos, dos mendigos e andarilhos?

Deve-se confessar que a lógica, da autora desta monografia, seus valores e preconceitos, bem como a forma complexa como Foucault trata a questão do saber, não só dificultaram o trabalho de identificação dos saberes construídos pelas crianças e pelos adolescentes de rua como, certamente, impediram a realização de uma análise mais consistente sobre essa questão.

Para auxiliar nas dificuldades teóricas utilizam-se os estudos empreendidos por Deleuze sobre o saber na perspectiva foucaultiana. De acordo com esse autor o saber para Foucault "...define-se por suas combinações do visivel e do enunciável próprias para cada estrato, para cada formação histórica” (Deleuze, 1991:60). O que não significa dizer que os dois pólos do saber sejam as coisas e as palavras, pois o saber não é só o visto e o dito, mas inclui o não visto e o não dito. $\mathrm{E}$ cabe ressaltar que cada época e cada lugar têm a sua maneira de ver e a sua forma de dizer.

\section{3 - A rua como lugar de formação}

Qualquer atividade humana precisa de um espaço e um tempo determinados.

"A ocupação do espaço, sua utilização, supõe sua constituição como lugar. O salto qualitativo do espaço em lugar, é, pois, uma construção. $O$ espaço se projeta ou imagina; o lugar 
se constrói desde o fluir da vida e, a partir do espaço como suporte. O espaç̧o, portanto, está sempre disponivel e disposto para converter-se em lugar, para ser construído"."

De acordo com essa concepção, é possível dizer que a rua, enquanto espaço, converte-se em lugar de formação de crianças e de adolescentes, no momento em que esses sujeitos passam a viver quotidianamente pelas calçadas. A rua não se constitui em um lugar de liberdade, em um caos, mas possui uma estrutura em parceria com a casa/instituição e, como tal, imprime em seus ocupantes um código de vivência que se encontra permeado por relações de poder-saber.

De acordo com Da Matta (1991:71) "[...] rua/casa se organizam tanto numa forma de oposição binária quanto em gradações (num continuum)". A visão dicotômica da rua está colocada na concepção de que a rua é o lugar do imprevisto, das relações impessoais, do perigo, da malandragem e a casa, o lugar do controle, da intimidade, da segurança. Ao passo que a idéia da gradação está posta na divisão espacial da casa, visto que a casa sempre tem um elo de comunicação com a rua, que pode ser a janela, a varanda que dá para o jardim, a sala de visitas, etc. É possivel dizer que rua e casa são os dois lados de uma mesma moeda e, portanto, não dá para falar de um espaço sem ter como referência o outro.

Conforme demonstram alguns estudos, o próprio cotidiano, a família, a escola e as instituições criadas especialmente para atender a esse contingente populacional, não têm conseguido mantê-los longe da rua, lugar que passa a ter um papel fundamental na socialização de considerável número de crianças e adolescentes empobrecidos.

\section{3 - Pressupostos Metodológicos}

Segundo Minayo (1994:16), a metodologia inclui "as concepções teóricas de abordagem, o conjunto de técnicas que possibilitam a construção da realidade e o sopro divino do potencial criativo do investigador."

Dir-se-ia, em outras palavras, que a metodologia é o caminho que o pesquisador utiliza para conhecer a verdade sobre determinada realidade. Mas,

"[...] a verdade não existe fora do poder ou sem poder [...]. Cada sociedade tem seu regime de verdade, sua "política geral" de verdade: isto é os tipos de discursos que ela acolhe e faz funcionar como verdadeiros; os mecanismos e as instâncias que permitem distinguir os enunciados verdadeiros dos falsos, a maneira como se sanciona uns e outros; as técnicas e os procedimentos que são valorizados para a obtenção da verdade; 0 estatuto daqueles que têm o encargo de dizer o que funciona como verdadeiro" (Foucault, 1993 b: 12).

Na sociedade ocidental, uma das características importantes da verdade é ser centrada na forma do discurso científico e nas instituições que o produzem (Foucault, 1993 b:13).

Mas o que é científico? Há muitos conflitos e contradições a este respeito. Um exemplo dessas disparidades seria o grande dilema que existe sobre a cientificidade das ciências sociais em comparação com as ciências da natureza.

Para resolver tal impasse:

FRAGO, Antonio Vinão. Del espacio escolar y la escula como lugar: propostas y cuestiones. In: Rev. De História de la Educacion. Salamanca: Ed. Universidade, Salamanca, n² 12-13, 1993 - 94. 
"Há os que buscam a uniformidade dos procedimentos para compreender o natural e o social como condição para atribuir o estatuto de "ciência" ao campo social. Há os que reivindicam a total diferença e especificidade no campo humano" (Minayo, 1994:10-11).

Há, por outro lado, também, aqueles que buscam uma mediação entre esses dois extremos. Dir-se-ia que a terceira opção foi a "escolhida", para tentar resolver o problema de pesquisa ora proposto:: como se vem efetivando o processo de formação das crianças e dos adolescentes de rua de Pelotas, entre os anos de 1983 a 1994 ?

Essa escolha fez-se em função, principalmente, da natureza do problema, e por se acreditar que os dados quantitativos e qualitativos não se opõem, mas ao contrário, complementam-se.

O principal instrumento de pesquisa foi a entrevista semi-estruturada, pois mesmo com um roteiro, existe a possibilidade de fazer adaptações, conforme a situação o exija. Certamente a escolha desse instrumental - entrevista- deve-se ao fato de que talvez se acredite poder produzir a verdade, a partir da confissão. Pois, como diz Foucault (1993 a:59) "o homem no Ocidente tornou-se um animal confidente".

Desde a Idade Média pelo menos, as sociedade ocidentais colocaram a confissão entre os rituais mais importantes para a produção da verdade. Confessam-se os crimes, as paixões, os pecados, a infância, a vida sexual, os sonhos, o cotidiano, etc.

A confissão é, para o autor, um ritual que se desenrola numa relação de poder, em que a instância de dominação não se encontra do lado do que fala, mas do lado de quem escuta e cala; não do lado do que sabe e responde, mas do que interroga e supostamente ignora (Foucault, 1993 a:62).

Além das entrevistas, são ainda utilizadas notícias veiculadas pelo jornal Diáno Popular, que também não deixam de ser a expressão de uma confissão, quer seja de uma autoridade judicial, policial, eclesiástica ou outra.

O importante é perceber que a produção da verdade está inteiramente infiltrada pelas relações de poder, e que a presente produção não foge a essa regra.

A hipótese central deste trabalho é que o processo de formação das crianças e dos adolescentes de rua efetiva-se através de relações de poder-saber estabelecidas no seu cotidiano. E mais, que "o poder é um instrumento de análise capaz de explicar a produção dos saberes" (Foucault, 1993 b: X).

Mas, como analisar as relações de poder para chegar à produção do saber e, conseqüentemente, à compreensão do processo de formação?

Após dois meses de busca incessante descobriu-se a resposta ao ler-se um texto de Foucault (1988) ${ }^{10}$ que dizia o seguinte: a análise das relações de poder exige o estabelecimento de um certo número de critérios, quais sejam:

“1) O sistema de diferenciações que permitem atuar sobre as ações dos outros: diferenças juridicas ou tradicionais de status e de privilégios; diferenças econômicas na apropriação das riquezas e dos bens; diferenças de ubiqüidade nos processos de produção; diferenças lingüísticas ou culturais; diferenças nas destrezas e nas competências e etc. Toda relação de poder pōe em marcha diferenciações que são ao mesmo tempo suas condições e seus efeitos.

10 O original desse texto está redigido em espanhol. 
2) $O$ tipo de objetivos perseguidos por aqueles que atuam sobre as ações dos outros: manter privilégios, acumular ganâncias, fazer funcionar a autoridade estatutária, exercer uma função ou um oficio.

3) As modalidades instrumentais: quer se exerça o poder pela ameaça das armas, pelos efeitos da palavra, através das disparidades econômicas, por mecanismos mais ou menos complexos de controle, por sistemas de vigilância, com ou sem arquivos, segundo regras explícitas ou não, permanentes ou modificáveis, com ou sem dispositivos materiais e etc.

4) As formas de institucionalização: essas podem mesclar disposições tradicionais, estruturas jurídicas, fenômenos relacionados com o costume ou a moda (como se vê as relações de poder que atravessam a instituição familiar); também podem tomar a forma de um dispositivo cerrado sobre si mesmo com seus lugares específicos, seus regulamentos próprios, suas estruturas hierárquicas cuidadosamente desenhadas, e uma relativa autonomia funcional (como as instituições militares ou escolares); podem formar, assim, sistemas muito complexos dotados de múltiplos aparatos, como o caso do Estado que tem como função constituir a envoltura geral, a instância de controle global, o princípio de regulação, em certa medida também, a distribuição de todas as relações de poder em um conjunto social dado.

5) Os graus de racionalização: a aposta em jogo de relações de poder como ação em um campo de possibilidades pode ser mais ou menos elaborada em função da eficácia dos instrumentos e da certeza do resultado ou também em função do custo eventual (custo econômico dos meios postos em prática ou custo em termos de reação constituída pelas resistências encontradas)" (Foucault, 1988:17-18).

Utilizam-se aqui esses cinco pontos para captar a dinâmica da formação das crianças e dos adolescentes de rua de Pelotas.

\section{4 - Alguns resultados da pesquisa}

Com este trabalho, produziu-se um saber a respeito de como ocorre o processo de formação das crianças e dos adolescentes de rua de Pelotas.

Constatou-se que as crianças e os adolescentes que vivem nas ruas de Pelotas, sofrem um processo de "rualização" que os torna diferenciados das demais pessoas. Isso ocorre, especialmente, pelo modo de vida que levam. E esse processo acontece através das relações de poder-saber que estabelecem, principalmente entre si, no mocó, e, também, com a Brigada Militar, a Polícia Civil, o Juizado da Infância e da Juventude e as obras assistenciais das quais participam.

Para demonstrar como se efetiva essa relação de poder-saber elaborou-se um quadro-resumo para cada uma dessas instâncias, levando-se em conta os cinco parâmetros indicados por Foucault e já abordados anteriormente.

O mocó é o lugar por excelência de formação daqueles que estão, hoje, nas ruas. Poder-se-ia dizer que ele é literalmente a "escola da rua", tendo inclusive sofrido uma forma de institucionalização, com regras e normas a serem cumpridas. Constitui-se no lugar alternativo construído pelas crianças e pelos adolescentes de rua, que se contrapõe às alternativas oficiais criadas pela sociedade. É nesse ambiente que os meninos e as meninas de rua se vão constituindo enquanto sujeitos. É entre quatro paredes de casas abandonadas que parte da infância e da juventude pelotense constrói uma maneira de ser e um modo de viver diferente de todos os outros de que se tem conhecimento. Nas relações de poder-saber que eles estabelecem entre si vão tornando-se crianças e adolescentes de rua. 
Quadro-Resumo 01

\begin{tabular}{|l|l|l|l|l|l|l|l|}
\hline & \multicolumn{3}{|c|}{$\begin{array}{l}\text { PONTOS PARA ANÁLISE DAS RELAÇÕES } \\
\text { DE PODER-SABER }\end{array}$} & \multicolumn{2}{c|}{$\begin{array}{l}\text { OS SABERES } \\
\text { CONSTRUtDOS }\end{array}$} \\
\hline $\begin{array}{l}\text { Instância } \\
\text { formadora }\end{array}$ & $\begin{array}{l}\text { Sistema } \\
\text { de diferen- } \\
\text { ciaçōes }\end{array}$ & Objetivos & Instrumentos & $\begin{array}{l}\text { Formas de } \\
\text { Institucio- } \\
\text { nalização }\end{array}$ & $\begin{array}{l}\text { Graus de } \\
\text { Raciona- } \\
\text { lização }\end{array}$ & $\begin{array}{l}\text { Visivel e } \\
\text { Enunciável }\end{array}$ & $\begin{array}{l}\text { Além do Visivel } \\
\text { e do Enunciável }\end{array}$ \\
\hline $\begin{array}{l}\text { Turma } \\
\text { do } \\
\text { Mocó }\end{array}$ & $\begin{array}{l}\text { experiência; } \\
\text { porte fisico; } \\
\text { idade; } \\
\text { destreza; } \\
\text { competência, } \\
\text { afeto }\end{array}$ & $\begin{array}{l}\text { sobreviver; } \\
\text { fugir da } \\
\text { repressāo; } \\
\text { construir } \\
\text { uma } \\
\text { identidade } \\
\text { de sujeitos } \\
\text { da rua }\end{array}$ & $\begin{array}{l}\text { efeitos da } \\
\text { palavra; } \\
\text { turma; } \\
\text { coação física } \\
\text { e droga }\end{array}$ & mocó & baixo & $\begin{array}{l}\text { roubar; } \\
\text { furtar; } \\
\text { drogar-se }\end{array}$ & $\begin{array}{l}\text { maneira alternativa } \\
\text { de sobreviver relaçōes } \\
\text { de poder-saber na } \\
\text { familia e/ou a situa- } \\
\text { cão econômica; } \\
\text { sobreviverem inde- } \\
\text { pendentes dos } \\
\text { adultos e das formas } \\
\text { convencionais }\end{array}$ \\
\hline
\end{tabular}

A partir do Quadro-Resumo 01, conclui-se que a idade, o porte físico, as habilidades, a experiência e a capacidade de estabelecer vínculos afetivos são aspectos que, juntos ou separadamente, têm condições de ampliar ou limitar o campo de ação daqueles que se encontram nos mocós. Essas diferenças são empregadas em função de um objetivo único: a sobrevivência. Para alcançarem tal objetivo, utilizam-se, preferencialmente, os efeitos da palavra (expressos concretamente através de convites, ameaças e pactos), da própria turma, da força física e da droga, especialmente, a cola. A eficácia desses instrumentos permite que o processo de "rualização" das crianças e dos adolescentes ocorra de uma forma bastante natural e espontânea, não sendo, portanto, necessário ações muito elaboradas para que os meninos e as meninas se tornem sujeitos da rua, que determina um baixo grau de racionalização das ações empreendidas pela turma do mocó entre seus membros.

Segundo os meninos e as meninas de rua, a turma do mocó funciona como escola e como familia. Aprendem nessas relações a sobreviver, a se utilizar, especialmente do roubo e da droga para se manter vivos. Mas, para além desses saberes, visiveis e enunciáveis, existem outros, não explicitados pelos entrevistados, mas evidenciados pela vida que levam e pelos discursos que realizam. Aprendem a viver sem acúmulo de bens materiais. Dispensam móveis, roupas, brinquedos, etc. É preciso saber viver com o mínimo, com o unitário, não ter apego às coisas materiais. Quem vive na rua não pode ter, por exemplo, dois pares de tênis, porque, certamente, não existirá lugar seguro para guardar o par "supérfluo", nem mesmo no mocó.

Ficou evidenciado neste estudo que as crianças e os adolescentes de rua também sofrem a influência da Brigada Militar, da Polícia Civil e do Juizado da Infância e da Juventude no seu processo de "rualização" o que pode ser visualizado no Quadro-Resumo 02. 
Quadro-Resumo 02

\begin{tabular}{|c|c|c|c|c|c|c|c|}
\hline \multirow[b]{2}{*}{$\begin{array}{l}\text { Instâncias } \\
\text { formadoras }\end{array}$} & \multicolumn{5}{|c|}{$\begin{array}{c}\text { PONTOS PARA ANÁLISE DAS RELAÇŌES } \\
\text { DE PODER-SABER }\end{array}$} & \multicolumn{2}{|c|}{$\begin{array}{l}\text { OS SABERES } \\
\text { CONSTRUIDOS }\end{array}$} \\
\hline & $\begin{array}{l}\text { Sistema } \\
\text { de Diferen- } \\
\text { ciaçőes }\end{array}$ & Objetivos & Instrumentos & $\begin{array}{l}\text { Formas de } \\
\text { Institucio- } \\
\text { nalizaçẫo }\end{array}$ & $\begin{array}{l}\text { Graus } \\
\text { de Racio- } \\
\text { nalizaçāo }\end{array}$ & $\begin{array}{l}\text { Visivel e } \\
\text { Enunciável }\end{array}$ & $\begin{array}{l}\text { Além do } \\
\text { Visivel e do } \\
\text { Enunciável }\end{array}$ \\
\hline $\begin{array}{l}\text { Brigada Militar, } \\
\text { Policia Civil } \\
\text { e Juizado } \\
\text { da Infância } \\
\text { e da } \\
\text { Juventude }\end{array}$ & $\begin{array}{l}\text { Represen- } \\
\text { tantes da } \\
\text { lei e da } \\
\text { ordem }\end{array}$ & $\begin{array}{l}\text { Punir coibir } \\
\text { práticas de } \\
\text { furto e/ou } \\
\text { roubo e uso } \\
\text { de drogas; } \\
\text { fazer } \\
\text { funcionar } \\
\text { a autoridade } \\
\text { policial, } \\
\text { militar } \\
\text { e judicial }\end{array}$ & $\begin{array}{l}\text { Extorsão } \\
\text { da confissão; } \\
\text { efeitos } \\
\text { da palavra } \\
\text { e analfabe- } \\
\text { tismo }\end{array}$ & $\begin{array}{l}\text { Visão e } \\
\text { tratamento da } \\
\text { criança e do } \\
\text { adolescente } \\
\text { de rua como } \\
\text { delinqüentes. } \\
\text { Com os projetos } \\
\text { AMAR e Beija- } \\
\text { Flor uma nova } \\
\text { forma de visuali- } \\
\text { zar esses sujeitos }\end{array}$ & $\begin{array}{l}\text { Baixo. } \\
\text { Com os } \\
\text { projetos, } \\
\text { tendência } \\
\text { é ser mais } \\
\text { alta }\end{array}$ & Nenhum & $\begin{array}{l}\text { A lei e a } \\
\text { violência } \\
\text { andam } \\
\text { juntas, } \\
\text { a transfor- } \\
\text { marem-se } \\
\text { em marginais }\end{array}$ \\
\hline
\end{tabular}

$O$ que permite $o$ estabelecimento de relações entre os meninos e as meninas de rua e esses segmentos representativos da lei é justamente a posição jurídica que ocupam na sociedade, e os atos de infração cometidos por aqueles, especialmente, o roubo e o uso da cola como substância alucinógena.

O principal objetivo dos representantes da lei é punir os "infratores" e/ou impedi-los de continuarem cometendo novos delitos. Para tal, utilizam-se da extorsão da confissão, aliada a um castigo físico; do analfabetismo dos "contraventores", dos efeitos da palavia (ameaças, injúrias e troca de favores). Com a utilização dessas modalidades instrumentais a Brigada, a Polícia e o Juizado transformam, na maioria das vezes, as crianças e os adolescentes de rua em marginais. Ao imporem limitações violentas e, portanto, contrárias às leis, institucionalizam uma forma de relacionamento extra-oficial, ilegal, com aqueles considerados marginais. A alternativa da ação violenta indica, entre outras coisas, que não há por parte dessas instituições um plano de intervenção, no sentido de evitar que as crianças e os adolescentes de rua deixem de praticar o roubo e/ou abandonem o uso de drogas. Evidenciando dessa forma um baixo grau de racionalização de suas ações e, portanto, a ineficácia dos instrumentos utilizados, o que reforça ainda mais a permanência desses meninos e dessas meninas nas ruas.

Por outro lado, a iniciativa da Brigada Militar, com a criação dos projetos AMAR e Beija-Flor, indica, em princípio, um grau maior de racionalização das ações empreendidas, o que só poderá ser verificado, a longo prazo, com o sucesso ou não, desses projetos.

As crianças de rua aprendem com as instâncias representativas da lei não só, a se reconhecerem como marginais mas também a assumirem tal papel.

Igualmente fazem parte do processo de "rualização" das crianças e dos adolescentes de rua, além da turma do mocó e das instâncias representativas da lei, as obras assistenciais destinadas ao atendimento dessa população. 
Foi possivel constatar, através dos depoimentos dos entrevistados, que as instituições em evidência, nessa pesquisa, visam retirar os meninos e as meninas das ruas e, dessa forma, reconstituir a ordem social. Buscam, assim, assumir as funções da família, na tentativa de suprirem as necessidades de moradia, alimentação, vestuários, educação, saúde, higiene, carinho, etc. dessa população em abandono. Assim, as obras assistenciais não agem, como a Polícia, a Brigada e o Juizado, especialmente sobre as ações de roubo e uso de droga dos meninos e das meninas de rua, mas, em função da própria ação de "abandono" em que esses se encontram.

\section{Quadro-Resumo 03}

\begin{tabular}{|l|l|l|l|l|l|l|l|}
\hline & \multicolumn{4}{|c|}{$\begin{array}{l}\text { PONTOS PARA ANÁLISE DAS RELAÇÕES } \\
\text { DE PODER-SABER }\end{array}$} & \multicolumn{2}{c|}{$\begin{array}{l}\text { OS SABERES } \\
\text { CONSTRUiDOS }\end{array}$} \\
\hline $\begin{array}{l}\text { Instância } \\
\text { formadora }\end{array}$ & $\begin{array}{l}\text { Sistema } \\
\text { de Diferen- } \\
\text { ciaçōes }\end{array}$ & Objetivos & Instrumentos & $\begin{array}{l}\text { Forma de } \\
\text { Institciona- } \\
\text { lização }\end{array}$ & $\begin{array}{l}\text { Graus de } \\
\text { Raciona- } \\
\text { lização }\end{array}$ & $\begin{array}{l}\text { Visivel e } \\
\text { Enunciável }\end{array}$ & $\begin{array}{l}\text { Além do } \\
\text { Visivel e do } \\
\text { Enunciável }\end{array}$ \\
\hline $\begin{array}{l}\text { Obras } \\
\text { Assis- } \\
\text { tenciais }\end{array}$ & $\begin{array}{l}\text { posição } \\
\text { hierárquica } \\
\text { e o saber }\end{array}$ & $\begin{array}{l}\text { permanência } \\
\text { na instituição } \\
\text { e disciplina }\end{array}$ & $\begin{array}{l}\text { efeito das } \\
\text { palavras; } \\
\text { pacto do faz } \\
\text { de conta; tempo; } \\
\text { normas e regras; } \\
\text { alimento; } \\
\text { trabalho; } \\
\text { recompensa } \\
\text { e punição }\end{array}$ & $\begin{array}{l}\text { fechadas com } \\
\text { estrutura e } \\
\text { normas } \\
\text { discrias;inada forma } \\
\text { de ver e tratar } \\
\text { a criança } \\
\text { e o adolescente } \\
\text { de rua }\end{array}$ & baixo & $\begin{array}{l}\text { saber-fazer: } \\
\text { habilidades } \\
\text { manuais e } \\
\text { saber-ser: } \\
\text { submissão e } \\
\text { resignaçăo. }\end{array}$ & $\begin{array}{l}\text { agirem } \\
\text { de modo } \\
\text { falso e a } \\
\text { repetirem } \\
\text { os discursos } \\
\text { permitidos. }\end{array}$ \\
\hline
\end{tabular}

Pelos depoimentos dos entrevistados, o que se pode perceber é que as instituições têm como objetivo imediato fazer funcionar a sua autoridade estatutária. Buscam exercer o controle daqueles que se encontram sob sua guarda. E isso só é possivel porque existe um sistema de diferenciações que é colocado em prática e aceito por todos os seus integrantes. Em especial, a hierarquia institucional e as diferenças culturais. As crianças e os adolescentes de rua devem respeito e obediência aos agentes institucionais considerados os representantes da ética e da moral a ser seguida. Entretanto, para que essas diferenças permitam controlar as ações dos institucionalizados, a instituição utiliza-se de inúmeros instrumentos tais como: os efeitos da palavra (o discurso da última chance, o conselho, o lema, a oração), o pacto do faz-de-conta, o tempo, as normas e as regras, o alimento, o trabalho, o sistema de recompensas e punições (livro de ocorrências, a suspensão e o castigo).

Tudo isso, em última instância, para formar corpos dóceis e submissos e não para fazê-los romperem com a vida na rua.

Essas instituições, assim como muitas outras, podem tornar-se fábricas de meninos e de meninas de rua. $\mathrm{E}$ isso é possivel ocorrer pelo tipo de existência das crianças e adolescentes, na maioria das vezes, ociosos, sem terem como ocupar o tempo, ou ocupados em atividades inúteis para as quais não encontrarão utilidade no mercado de trabalho. Isso evidencia um baixo grau de racionalização das ações 
empreendidas, e conseqüentemente, a ineficácia das modalidades instrumentais utilizadas para que se alcancem os objetivos em relação à clientela atendida.

Os entrevistados afirmam que as obras assistenciais estão preocupadas em ensiná-los a serem educados e capazes de desenvolverem algum tipo de atividade manual. Mas na verdade aprendem a negar sua própria identidade, a se envergonhar do que são e a assumir uma falsa identidade. Talvez esse seja um dos motivos que explique o insucesso de experiências que visam retirar as crianças e os adolescentes das ruas, pois as instituições não atuam sobre os problemas que a crianças e o adolescente de rua trazem consigo, como, por exemplo, a questão da droga, mas sobre um ideal de infância e de juventude que nada tem a ver com a realidade dos institucionalizados, obrigando-os a um comportamento fingido, falso e, portanto, vulnerável a recaídas.

Assim como os mocós e as instâncias representativas da lei, também as obras assistenciais podem favorecer a organização de um meio delinqüente, solidário, hierarquizado, aberto a todas as cumplicidades presentes e futuras.

\section{5 - Considerações finais}

Ainda que não tenha sido esboçada uma proposta metodológica para solução da questão da criança e do adolescente de rua, pretende-se ter indicado com o presente trabalho, não só quem são os principais agentes formadores no âmbito da rua, como ter demonstrado a maneira como ocorre o processo de formação desses sujeitos. Entende-se ser possível, a partir das constatações realizadas, apontar algumas indicações e, quem sabe, despertar outras tantas, naqueles que tomarem contato com este estudo.

Assim, levantam-se aqui alguns pontos para reflexão:

- Os prédios históricos, transformados em mocós, não poderiam ser utilizados como centros de formação daqueles que os habitam?

- Não seria o adolescente de rua, ele mesmo, um agente formador a ser utilizado para o trabalho com crianças de rua?

- A criação de um comitê de recepção oficial, capaz de detectar os que estão chegando na rua e capaz de com eles trabalhar, não seria uma forma preventiva de evitar o processo de "rualização" dos mesmos?

- O tratamento para a drogadição não deveria necessariamente fazer parte de qualquer trabalho que pretenda atender crianças e/ou adolescentes de rua?

- A Polícia Civil, o Juizado da Infância e da Juventude e a Brigada Militar" não teriam que se preocupar com uma formação para os seus agentes no que diz respeito ao trato com a criança e o adolescente de rua?

- Uma ação integrada, especialmente entre essas três instâncias, não poderia proporcionar uma nova maneira de ver e de tratar a questão?

"A intenção não é desconsiderar o trabalho que a Brigada Militar vem desenvolvendo, mas reforçar a necessidade de se terem pessoas constantemente preparadas para lidarem com a questão. 
- As instituições não deveriam repensar, especialmente, os seus objetivos e as suas modalidades instrumentais no trato com os seus institucionalizados?

Não há dúvidas de que muitas outras indagações poderão surgir, entretanto, uma deverá permanecer sobre as demais. Uma dúvida que sempre acompanhou Foucault em seus trabalhos: será que não há uma outra maneira de ver e de pensar aquilo que está posto como verdade definitiva?

Nesse trabalho, pretendeu-se produzir uma verdade a respeito de como ocorre o processo de formação das crianças e adolescentes de rua, em Pelotas. De outra parte, segundo Foucault (1993 b:14), "a verdade está circularmente ligada a sistemas de poder, que a produzem e a apoiam, e a efeitos de poder que ela induz e que a reproduzem". Em suma, a verdade é poder. E aí é de perguntar-se: O que faz com que as coisas que aqui estão ditas sejam consideradas verdadeiras? Foucault, certamente, responderia que o regime de verdade do qual fazemos parte. ${ }^{2}$

\section{Referências bibliográficas}

COUTINHO, Ismael de Lima. Pontos de Gramática Histórica. 7. ed. rev. Rio de Janeiro: Ao Livro Técnico, 1976.

DAMATTA, Roberto. A casa \& a rua - espaço, cidadania, mulher e morte no Brasil. 4. ed. Rio de Janeiro: Guanabara Koogan S. A., 1991.

DELEUZE, Gilles. Foucault. Trad. Cláudia Sant'Anna Martins. 2. ed. São Paulo: Brasiliense, 1991.

DESAULNIERS, Julieta Beatriz Ramos. Trabalho: a escola do trabalhador? Tese de Doutorado, defendida em 1993, junto ao PPSEd / UFRGS.

FERREIRA, Aurélio Buarque de Holanda. Novo dicionánio da língua portuguesa. Rio de Janeiro: Nova Fronteira, 1975.

FOUCAULT, Michel. A arqueologia do saber. Trad. de Luis Felipe Baeta Neves. 3. ed. Rio de Janeiro: Nova Fronteira, 1975.

— . El sujeto y el poder. Revista Mexicana de Sociologia, México n. 3, ano L.p. 2-20, 3/88.

. História da sexualidade I - A vontade de saber. 11. ed. Trad. de Maria T. da C. Alburqueque e J. A. G. Alburqueque.Rio de Janeiro: Graal, 1993 a.

- Microfisica do poder. 11. ed. Org. e Trad. de Roberto Machado. Rio de Janeiro: Grau, 1993 b.

FRAGO, Antonio Viñao. Del espacio escolar y la escuela como lugar: propuestas y cuestiones. In: Rev. De História de la Educación. Salamanca: Ed. Universadade Salamanca, $n^{2} 12-13,1993-94$.

MACHADO, Roberto. Ciência e saber - a trajetória da arqueologia de Foucault. 2. ed. Rio de Janeiro: Graal, 1981.

MINAYO, Maria Cecília de Souza (Org.) et. al. Pesquisa Social - teoria método e criatividade. 2. ed. Petrópolis: Vozes, 1994.

SUDBRACK, Maria Fátima Oliver. A trajetónia da criança marginalizada rumo à delinqüência. Porto Alegre, 1982 (Dissertação de Mestrado).

12 'Em nossas sociedades, a 'economia política' da verdade tem cinco características historicamente importantes: a 'verdade' é centrada na forma do discurso científico e nas instituições que o produzem; está submetida a uma constante incitação econômica e política (necessidade de verdade tanto para a produção econômica, quanto para o poder político); é objeto de várias formas, de uma imensa difusāo e de um imenso consumo (circula nos aparelhos de educação ou de informação, cuja extensão no corpo social é relativamente grande, não obstante algumas limitaçōes nigorosas); é produzida e transmitida sob o controle, não exclusivo, mas dominante, de alguns grandes apareIhos politicos ou econômicos (universidade, exército, escritura, meios de comunicaçāo); enfim, é objeto de debate político e de confronto social (as lutas ideológicas)" (Foucault, 1993 b:13). 